\title{
EDITORIAL
}

\section{EL PLAN NACIONAL DE PREVENCIÓN Y CONTROL DEL TABAQUISMO Y EL MOVIMIENTO DE PREVENCIÓN EN ESPAÑA}

\author{
Joan R Villalbí \\ Comité Nacional de Prevención del Tabaquismo.
}

Desde hace años, las autoridades sanitarias españolas han identificado correctamente el consumo de tabaco como la mayor fuente de mortalidad evitable y prematura en nuestro país. Sin embrago, este diagnóstico no se ha acompañado del esfuerzo necesario para cambiar esta situación. Pese a la retórica, las políticas públicas de eficacia demostrada para reducir la magnitud de los daños que causa el tabaco, identificadas por la Organización Mundial de la Salud desde su primer plan de acción a finales de los años ochenta, apenas se habían desarrollado en España. Los presupuestos y la legislación no han reflejado la prioridad teórica del problema. Ha habido un rico abanico de iniciativas locales y de muchos profesionales heroicos, aunque huérfanos de recursos y coordinación, que no han podido compensar la falta de compromiso institucional durante este periodo.

Hoy sabemos que la falta de desarrollo de políticas contra el tabaco no es casual: los documentos internos de la industria tabaquera revelados en los Estados Unidos por acciones judiciales, nos han permitido conocer los planes estratégicos diseñados desde finales de los años ochenta para abortar la

Correspondencia:

Joan R Villalbí

Comité Nacional de Prevención del Tabaquismo

C/ Fuencarral, 18, 1D

28004 Madrid aprobación de políticas de control del tabaquismo en España, o para debilitarlas y dificultar su aplicación efectiva en caso de ser aprobadas. El movimiento de prevención, aglutinado desde 1996 en torno al Comité Nacional de Prevención del Tabaquismo, se esforzó siempre en fomentar la aprobación de una estrategia global de prevención, fundada en tres pilares: control de la publicidad, una política fiscal disuasoria, y la ampliación efectiva de los espacios sin humo. Junto con la ayuda a los fumadores para dejar de fumar, estas tres políticas constituyen las bases sobre las que se han asentado los progresos conseguidos por los países que han avanzado más en la reducción del consumo de tabaco. Hasta hace poco, en nuestro país esto era utópico, ya que la agenda del movimiento de prevención, que se orienta a desnormalizar el fumar, no era la de las autoridades sanitarias.

Sin embargo, podemos estar en puertas de cambios importantes. La aprobación del Plan Nacional de Prevención y Control del Tabaquismo en enero de 2003 por el Consejo Interterritorial de Salud es un cambio cualitativo: comporta la adopción de una agenda integral de prevención común por parte de las autoridades sanitarias del Ministerio de Sanidad y Consumo y las de las Comunidades Autónomas. Es por tanto un gran paso adelante, que permite esperar nuevos progresos. En su formulación actual, el 
Plan propone una batería de objetivos, Los que se refieren a la regulación de la promoción, la venta y el consumo del tabaco no requieren recursos, pero sí una fuerte voluntad política para conseguirse de manera efectiva. Los que se refieren a estimular la cesación necesitan recursos de apoyo a los fumadores que quieren dejar de fumar, en diversas formas, cuya disponibilidad no está aún plenamente garantizada. En cualquier caso, plantean nuevos retos que precisan de acciones concretas para pasar de la esfera de los buenos deseos al terreno de los hechos. Con un horizonte muy claro: porque cuanto antes se ejecuten antes notaremos su impacto en la salud pública: en el consumo de tabaco, en la proporción de fumadores, en las enfermedades, incapacidades, sufrimiento y número de muertes evitadas. Un objetivo compartido en el que las autoridades sanitarias pueden contar con la implicación, la colaboración e incluso el constante y leal estímulo del movimiento de prevención. 